\title{
Pilot-Scale Study of Real Domestic Textile Wastewater Treatment Using Cassia fistula Seed-Derived Coagulant
}

\author{
Minh-Trung Dao $\left(\mathbb{D},{ }^{1}\right.$ Vo-Chau-Ngan Nguyen $\left(\mathbb{D},{ }^{2}\right.$ Thanh-Nha Tran $\left(\mathbb{D},{ }^{1}\right.$ \\ Xuan-Du Nguyen $\mathbb{D}^{\mathrm{D}}{ }^{3}$ Duc-Thuong Vo $\mathbb{D}^{1},{ }^{1}$ Van-Kieu Nguyen $\mathbb{( D )},{ }^{4,5}$ \\ and Le-Thuy-Thuy-Trang Hoang $\mathbb{D}^{1}$ \\ ${ }^{1}$ Department of Environmental Engineering, Thu Dau Mot University, Thu Dau Mot City, Binh Duong, Vietnam \\ ${ }^{2}$ Can Tho University, Can Tho City, Vietnam \\ ${ }^{3}$ Sai Gon University, Ho Chi Minh City, Vietnam \\ ${ }^{4}$ Institute of Fundamental and Applied Sciences, Duy Tan University, Ho Chi Minh City 700000, Vietnam \\ ${ }^{5}$ Faculty of Natural Sciences, Duy Tan University, Da Nang 550000, Vietnam \\ Correspondence should be addressed to Minh-Trung Dao; trungdm@tdmu.edu.vn, Van-Kieu Nguyen; \\ nguyenvankieu2@duytan.edu.vn, and Le-Thuy-Thuy-Trang Hoang; tranghltt@tdmu.edu.vn
}

Received 3 June 2021; Revised 7 July 2021; Accepted 10 July 2021; Published 21 July 2021

Academic Editor: Rabia Rehman

Copyright (c) 2021 Minh-Trung Dao et al. This is an open access article distributed under the Creative Commons Attribution License, which permits unrestricted use, distribution, and reproduction in any medium, provided the original work is properly cited.

\begin{abstract}
Plant-derived coagulants have exhibited a good potential in wastewater treatment due to their "green" characteristics, high coagulating-flocculating activity, cost-effectiveness, and biodegradability. Nevertheless, research studies have focused mainly on bench-scale experiments; pilot-scale and full-scale simulations are still limited. Herein, we firstly report a pilot-scale study of real domestic textile wastewater treatment using Cassia fistula coagulant. The material characterizations using Fourier-transform infrared spectroscopy (FTIR), scanning electron microscope (SEM), and dynamic light scattering (DLS) revealed that the natural gum extracted from C. fistula seed possessed a rough and irregular surface containing a high molecular weight galactomannan. The bench-scale investigation was initially conducted to determine the optimal pollutant concentration, initial $\mathrm{pH}$, and coagulant dosage in the coagulation-flocculation process. The pilot-scale study revealed that $C$. fistula coagulant is an effective material for real textile wastewater treatment, showing percentage removal of $93.83 \%$ at a volume of $30 \mathrm{~L}$ and a coagulant dosage of $1.17 \mathrm{mg} \cdot \mathrm{L}^{-1}$. Coagulation-flocculation using C. fistula seed gum could be an efficient primary wastewater treatment prior to membrane or biological methods to meet Vietnamese environmental standards. The main mechanisms of textile wastewater treatment involve adsorption/bridging interactions via hydrogen bonding and electrostatic attraction between negatively charged carboxylate groups of the coagulant and positively charged pollutants.
\end{abstract}

\section{Introduction}

Water pollution has long been a global issue that has increased day by day due to the rapid pace of industrialization and population growth [1]. Watercourses have been contaminated by heavy metals, dyes, toxic anions, or organic compounds resulting from both anthropogenic activities and natural weathering processes [2-4]. Dyes are among important classes of pollutants in water sources [5]. They are a necessity in dyestuffs, textiles, paper, and plastics to impart color [6].
Due to the presence of numerous hazardous chemicals, discharge of dyes into aquatic bodies without proper purification causes significant health hazards [7-9]. The existence of sulfur, heavy metals, nitrates, and naphthol leads to skin irritation, liver damage, or dysfunction of the kidney. Aromatic amines, formaldehyde, chlorine, and hydrocarbonbased dyeing chemicals are reported to be carcinogenic $[10,11]$. Moreover, dyes also cause environmental problems due to imparting an undesirable color to the water body, resulting in blocking sunlight penetration and resisting the 
photosynthesis and respiration of living things [12]. The use of dyes generates a considerable amount of toxic colored wastewater; however, most of them are discarded into environmental water bodies without further treatment [12]. For these reasons, the removal of dyes from different types of wastewater streams is of worldwide concern.

Focuses on specific methods to remove these toxic substances from water sources have been sought. Present treatment methods and technologies include ion-exchange, adsorption, membrane filtration, chemical oxidation, coagulation-flocculation, electrochemical methods, and biological treatments $[9,10,12-16]$. The membrane filtration is effective for water recover and reusing, but the investment costs are often too high for small and medium industries $[12,15]$. The electrochemical destruction, oxidation, and ion-exchange are efficient methods of addressing toxic dyes; however, their high operating costs and energy consumption pose challenges to the application in real wastewater treatment [12]. The adsorption and coagulation-flocculation techniques are two popular methods for dye removal in industrial wastewater due to their easy of operation, cost-effectiveness, and high efficiency $[10,16]$. Global water industries consider coagulationflocculation to be one of the major treatment approaches to reduce cost and enhance the overall efficiency of practical treatments of wastewater [17]. It is a process of destabilizing and combining colloids, dissolved organic substances, or particles into larger aggregates [18]. These impurities could be further settled, filtered, and removed from the bulk medium in subsequent processes [17].

Conventional coagulants used in coagulation-flocculation procedures are aluminum-based and iron-based compounds [19]. The large amounts required and their toxic leftover residues are unavoidable drawbacks of these synthesized chemicals $[12,19]$. The discovery and development of coagulants from natural sources are therefore significantly important. Plant-derived coagulants are promising alternative substances due to their high efficiency, environmental friendliness, and cost-effectiveness [20-25]. Among various natural coagulants, Cassia fistula seed gum has been recognized as a potential material for wastewater treatments [22-24]. Moreover, in Vietnam, the use of C. fistula seed has the advantages of being abundantly distributed and considered as a common solid waste [22]. To the best of our knowledge, the use of plant-derived coagulants, especially for C. fistula seed in wastewater treatment has been mainly reported at a bench scale. Pilot-scale studies for evaluating the practical applications of $C$. fistula-based coagulant have not been previously reported.

In this study, a natural coagulant prepared from C. fistula seed was applied in the removal of Reactive Red 195 (RR-195) and real domestic textile wastewater. The effects of $\mathrm{pH}$, initial concentration of the dye, and coagulant dosage on the removal efficiency in a bench-scale simulation were investigated. A pilot-scale study was further conducted to evaluate the practical application of C. fistula coagulant in wastewater treatment to meet Vietnamese environmental standards.

\section{Materials and Methods}

2.1. Chemicals. Hexane, ethanol, $\mathrm{H}_{2} \mathrm{SO}_{4}, \mathrm{NaOH}$, and RR195 were of analytical grade and used as received. Raw C. fistula seeds were collected in Thu Dau Mot city, Binh Duong province, Vietnam. The real textile wastewater was collected from Nam Tan Uyen Industrial Park, Binh Duong province, Vietnam.

2.2. Preparation of Natural Gum from C. fistula Seed. The raw C. fistula seeds were dried under direct sunlight, and then the whole seeds were ground into powder. The extraction was performed using hexane as a solvent in a Soxhlet system. The fibrous mass was produced by ethanol precipitation after $48 \mathrm{~h}$. The solid material was washed with distilled water and dried at $50^{\circ} \mathrm{C}$ in air for $2 \mathrm{~h}$ to obtain C. fistula seed gum.

2.3. Material Characterization. The surface morphology of the as-synthesized gum was monitored by SEM using a Hitachi S4800 scanning electron microscope. The FTIR spectra were recorded using a FTIR/NIR spectrometer (Frontier/PerkinElmer, USA). A Malvern Zetasizer NanoZS dynamic light scattering instrument was employed to determine the zeta potential of C. fistula seed gum in aqueous solution.

2.4. Coagulation-Flocculation Process. The coagulationflocculation process of dye and textile wastewater treatment was performed using a jar test apparatus. It was equipped with a series of six beakers containing $1 \mathrm{~L}$ of waste solution for each test run. The $\mathrm{pH}$ of the mixture was adjusted using $1 \mathrm{M} \mathrm{H}_{2} \mathrm{SO}_{4}$ or $1 \mathrm{M} \mathrm{NaOH}$. The experiment was conducted for $5 \mathrm{~min}$ with initial rapid mixing (coagulation) at $200 \mathrm{rpm}$ after the addition of each coagulant(s), followed by a slow mixing stage for $5 \mathrm{~min}$ at $20 \mathrm{rpm}$ (flocculation). The floc was allowed to settle for $30 \mathrm{~min}$. After obtaining two layers, the supernatant was collected and examined for the reduction in color.

The removal efficiency of color was calculated using equation (1) as follows:

$$
\operatorname{removal}(\%)=\frac{\left(C_{0}-C_{e}\right)}{C_{0}} \times 100,
$$

where $C_{0}$ and $C_{e}$ are the initial and equilibrium concentration of dye in solution, respectively.

A pilot-scale treatment of dye and real textile wastewater with C. fistula seed gum was carried out to evaluate its practical application. A simulation diagram of the pilot-scale system is shown in Figure 1. A 30-L volume of pollutants was used for each test run. The removal process consisted of three consecutive stages similar to the jar test: rapid mixing (200 rpm, $5 \mathrm{~min}$ ), slow mixing ( $20 \mathrm{rpm}, 5 \mathrm{~min}$ ), and quiescent gravity separation $(30 \mathrm{~min})$. The supernatant was then collected and examined for validation purposes. The removal efficiency of the pilot-scale treatments was also calculated by equation (1). 


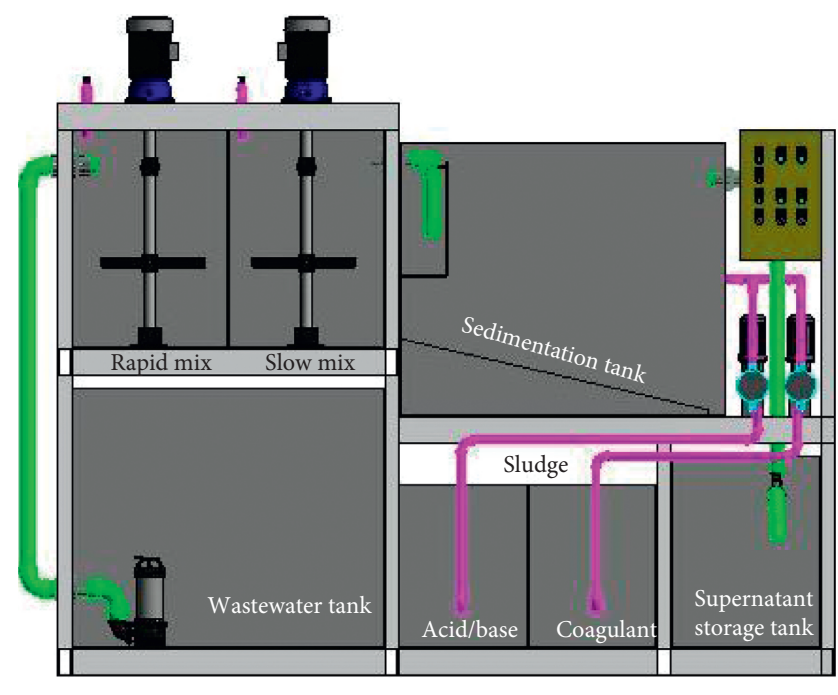

(a)

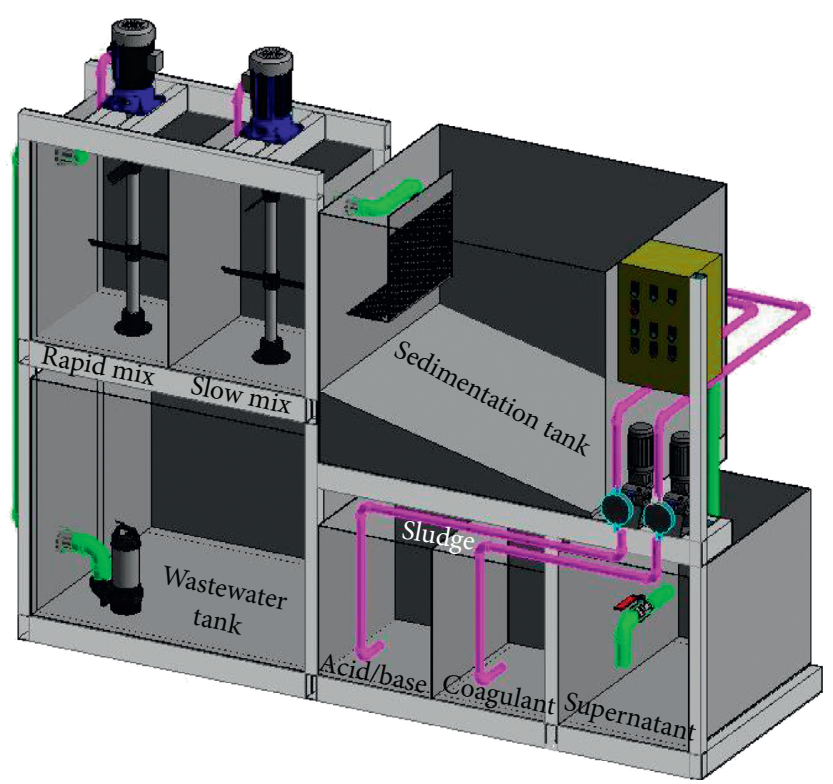

(b)

FIgure 1: A simulation diagram of the pilot-scale system used for the treatment of wastewater.

\section{Results and Discussion}

\subsection{Characterizations of C. fistula Seed Gum}

3.1.1. FTIR. Functional groups in the C. fistula seed gum were identified by FTIR in the range of 4000 to $450 \mathrm{~cm}^{-1}$ (Figure 2(a)). The broad bands at $3448 \mathrm{~cm}^{-1}$ and $2935 \mathrm{~cm}^{-1}$ could be attributed to the $-\mathrm{OH}$ stretching of carboxylic acid or alcohol and the $\mathrm{C}-\mathrm{H}$ stretching of aliphatic structures, respectively [26]. The absorption bands at $1423 \mathrm{~cm}^{-1}$ and $1642 \mathrm{~cm}^{-1}$ could represent $\mathrm{C}=\mathrm{C}$ (aromatic) and adsorbed water molecules, respectively [21, 23]. The vibrations of $\mathrm{C}-\mathrm{O}$ in $\mathrm{C}-\mathrm{OH}$ bonds could be observed in the broad band between $960 \mathrm{~cm}^{-1}$ and $1180 \mathrm{~cm}^{-1}$. The peak at $876 \mathrm{~cm}^{-1}$ and $814 \mathrm{~cm}^{-1}$ were related to the presence of anomeric deformation of $\beta$-d-mannopyranose and $\alpha$-d-galactopyranose, respectively [27], indicating the presence of galactomannans in the C. fistula seed gum in this study. Galactomannans are neutral polysaccharides, consisting of a skeleton with straight chain of $(1 \longrightarrow 4)-\beta$-d-mannopyranose units and single $(1 \longrightarrow 6)$ - $\alpha$-d-galactopyranose attached to main chain unit [28]. They can be extracted from the endosperm of the seeds of certain leguminous plants, such as Senna tora [26], Cassia obtusifolia [29], C. fistula [27], and Cassia grandis [28]. These polysaccharides have been recognized to be promising natural coagulants for wastewater treatment possessing advantages of posing minimal health risk to living organisms and forming biodegradable sludge [30].

3.1.2. SEM. The surface morphology of C. fistula seed gum displayed an irregular shape (Figure 2(b)). The presence of fibrous networks was observed, with rough surface and porosity, providing greater specific surface area and more adsorption sites. As a result, these properties might benefit the coagulation-flocculation process by improving the adsorption and bridging ability [20].

3.1.3. DLS. The average zeta potential of C. fistula seed gum measured by DLS in aqueous solution was $-15.7 \mathrm{mV}$ (Figure 3). This relatively high negative potential value indicated a stable and dispersed gum in aqueous solution. This can be attributed to negative-negative repulsion of carboxylate groups $\left(\mathrm{COO}^{-}\right)$on the surface of the seed gum as also observed in other polysaccharides derived from Alyssum homolocarpum seed gum [31] and chia seed gum [32].

3.2. Dye and Real Textile Wastewater Treatments. The coagulation-flocculation processes for dye and real textile wastewater treatments were performed using C. fistula seed gum. The prefeasibility studies to screen out important factors influencing the removal efficiency were carried out on a jar test apparatus. The pilot-scale coagulation-flocculation plant was further studied to simulate full-scale wastewater treatment.

3.2.1. Screening Experiments at Bench Scale for Optimal Initial Concentration of RR-195, Dosage, and $p H$ Conditions. The effect of initial concentration of RR-195 on decolorization is demonstrated in Figure 4. The removal efficiency dropped when initial concentration of RR-195 increased. This could be explained by the natural coagulant being exhausted when the initial concentration of RR-195 increased, due to the saturation of pollutant on its surface. Therefore, a higher dosage of coagulant was required to treat pollutants at higher initial concentration in order to provide a greater number of sites for adsorption, bridging, or electrostatic attraction. 


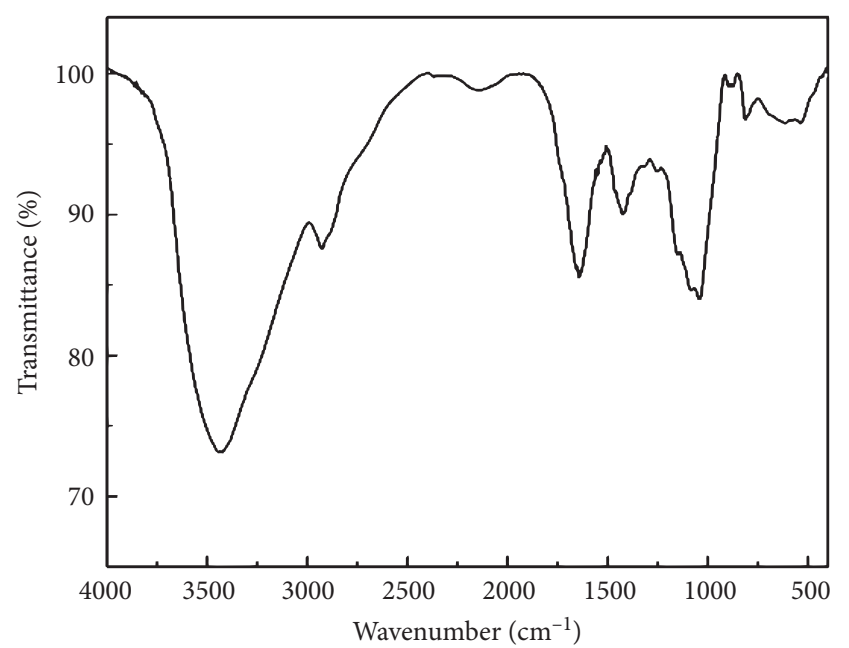

(a)

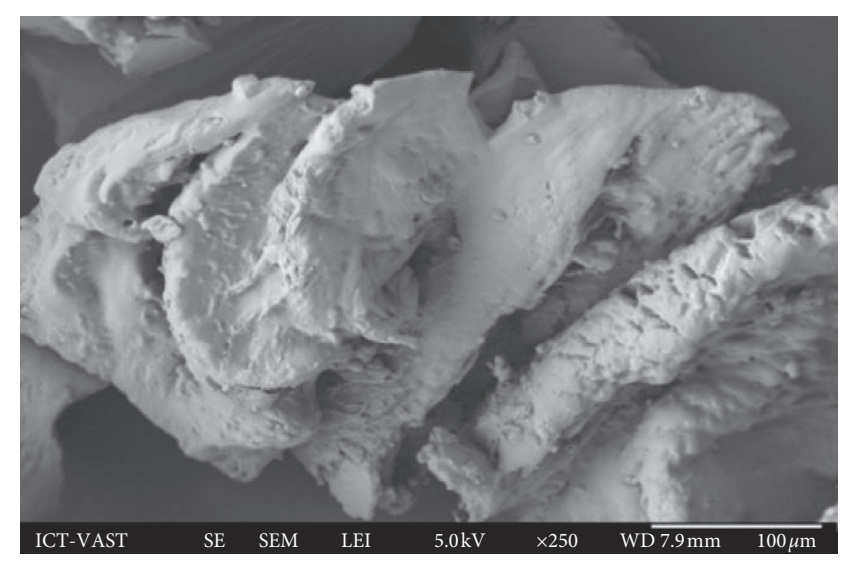

(b)

FIgURE 2: FTIR spectrum (a) and SEM image (b) of C. fistula seed gum.

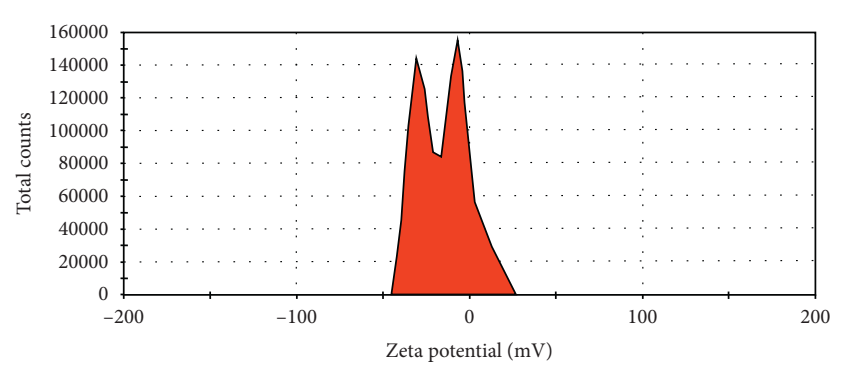

Figure 3: Zeta potential of C. fistula seed gum.

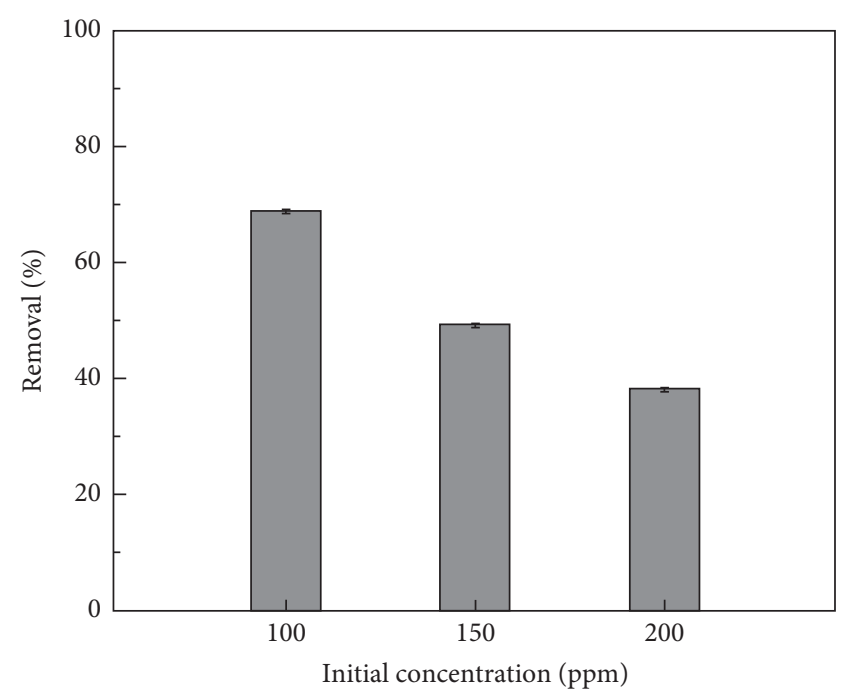

FIgURE 4: Effect of initial concentration of RR-195 on color removal.

$\mathrm{pH}$ is a critical variable affecting removal efficiency in the coagulation-flocculation process. The experimental studies on the effect of $\mathrm{pH}$ were therefore carried out in the initial $\mathrm{pH}$ range of 1-11 (Figure 5). The removal of RR-195 and treatment of real textile wastewater by C. fistula seed gum was found to be dependent on $\mathrm{pH}$, with different behaviors. For RR-195, the removal efficiency was much higher at lower pH. RR-195 is an anionic dye, and the natural coagulant possesses a more negatively charged surface at higher $\mathrm{pHs}$ due to deprotonation. Hence, electrostatic repulsion would be seen at higher $\mathrm{pH}$. Moreover, the possibility that C. fistula seed gum performed better at lower $\mathrm{pH}$ was attributed to the protonation of the coagulant that promoted better adsorption and bridging through hydrogen bonding. For textile wastewater, containing multiple textile dyes, inorganic salts, and organic additives [33], removal by coagulation would be more complicated. Adsorption/bridging and electrostatic attraction might occur simultaneously during this coagulation-flocculation process. In the $\mathrm{pH}$ range of $1-7$, the removal efficiency for real textile wastewater displayed a variation tendency similar to that of RR-195 due to a better adsorption through $\mathrm{H}$-bonding. When the $\mathrm{pH}$ was increased from 7 to 11, the removal of color was improved. This can be attributed to the fact that more negative charges were created on the surface of the coagulant at higher $\mathrm{pH}$ due to a partial deprotonation, resulting in an enhancement of electrostatic attraction between cationic dyes and the negatively charged coagulant.

Coagulant dosage is another important factor in the coagulation-flocculation process. The study of this factor could be of benefit not only for economic evaluation purposes but also to prevent the excessive use of coagulant during wastewater treatment [30]. The effect of dosage of C. fistula seed gum on the removal of RR-195 and textile wastewater is presented in Figure 6. The removal efficiency for both types of pollutant initially increased with the increase in coagulant dosage and decreased slightly with a further increase in dosage. Under low coagulant dosage, the collision between coagulant and pollutants was insufficient to destabilize pollutants, leading to lower treatment efficiency [34]. However, excess coagulant dosage led to the restabilization of coagulant flocs, resulting in low effectiveness of the solid-liquid separation process [35]. 


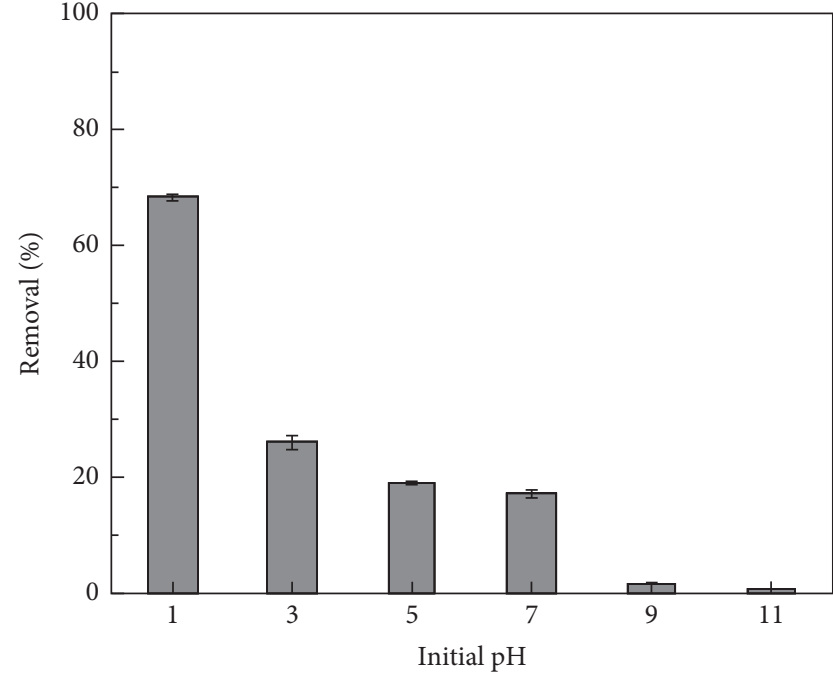

(a)

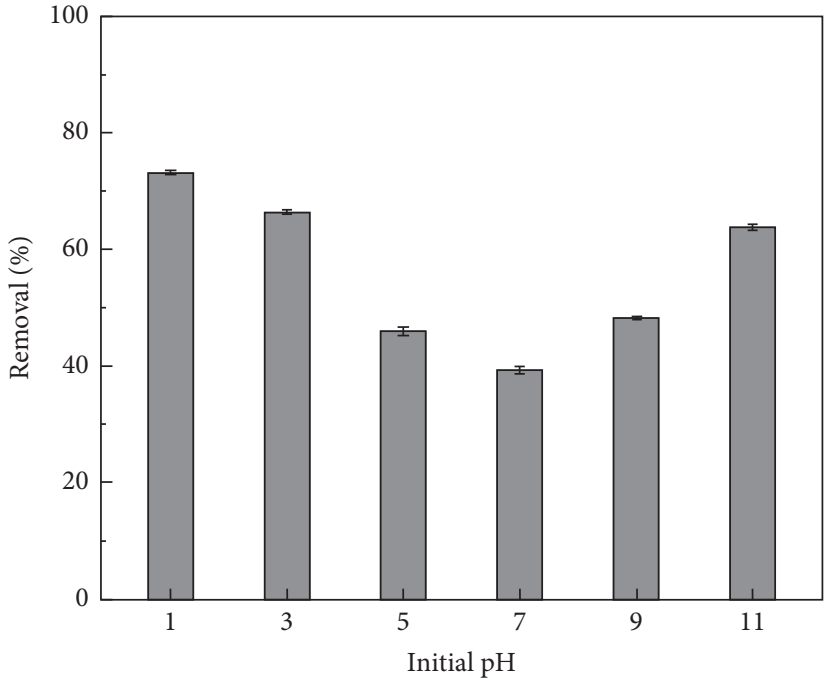

(b)

Figure 5: Effect of $\mathrm{pH}$ on dye (a) and real textile wastewater (b) treatments.

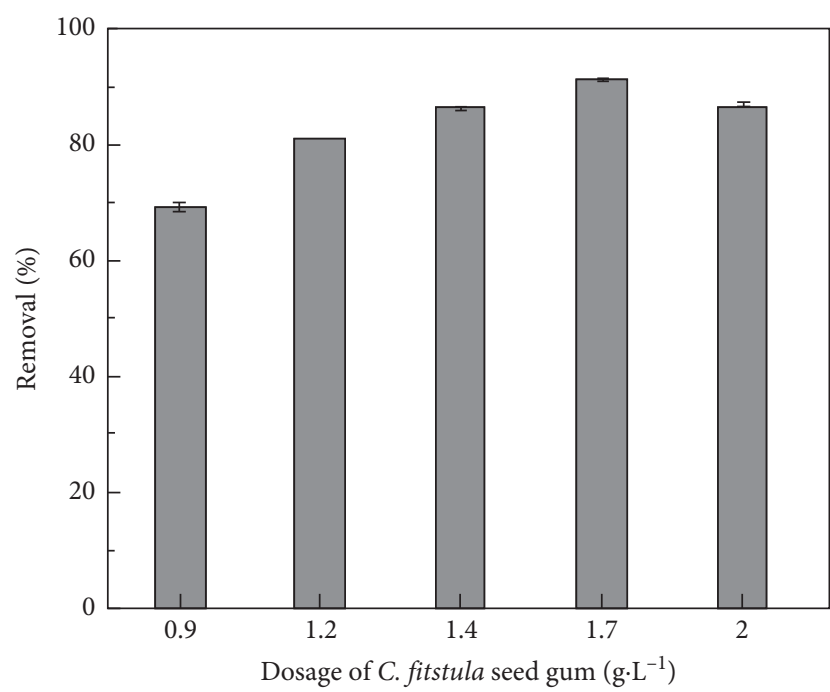

(a)

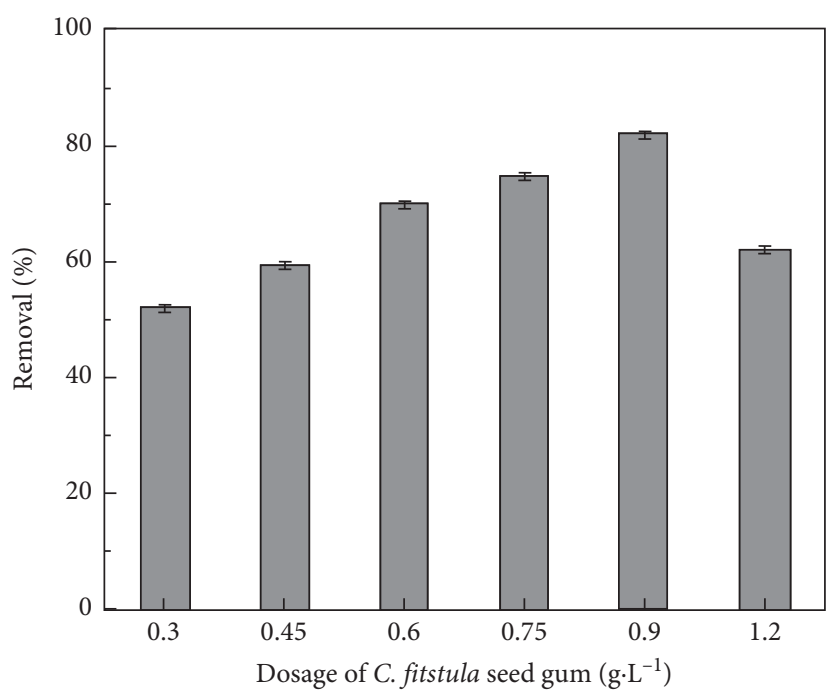

(b)

Figure 6: Effect of coagulant dosage on dye (a) and real textile wastewater (b) treatments.

3.2.2. Pilot-Scale Study of Real Textile Wastewater Treatment. After performing the bench-scale study using a jar test apparatus, a pilot-scale test was carried out to simulate full-scale textile wastewater treatment in a more detailed way. These pilot-scale experiments were designed based on the allowable pollution parameters of Vietnamese environmental standards. For the color factor, the national technical regulation on the limits for industrial wastewater (QCVN 40:2011/BTNMT) discharging into the water sources serving or not serving tap water supply are $50 \mathrm{ppm}$ (Column A) and $150 \mathrm{ppm}$ (Column B), respectively [36, 37]. From an initial color concentration, the required percentage removals to ensure these two values for textile wastewater were calculated (Table 1). The dosages of $C$. fistula needed for the pilot-scale study were further approximated based on the linear plot of percentage removal and dosage found in the bench-scale experiments (Figure 7). After performing the pilot-scale study, the final color concentrations obtained were $85.33 \mathrm{ppm}$ and $195.33 \mathrm{ppm}$ for column A and column B, respectively. These results slightly exceeded the regulated limits. However, this is reasonable as the coagulationflocculation method is used mainly as a pretreatment prior to membrane or biological treatments [38, 39]. Highstrength wastewater is treated primarily by this technique to reduce the cost of the secondary stage by reducing the 
TABle 1: Pilot-scale study of real textile wastewater treatment.

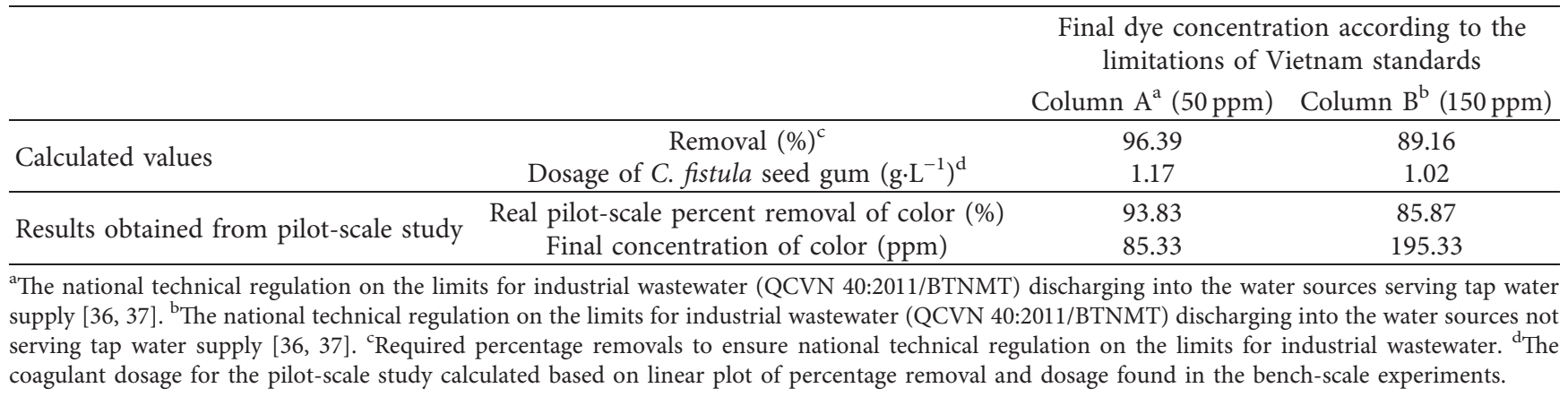

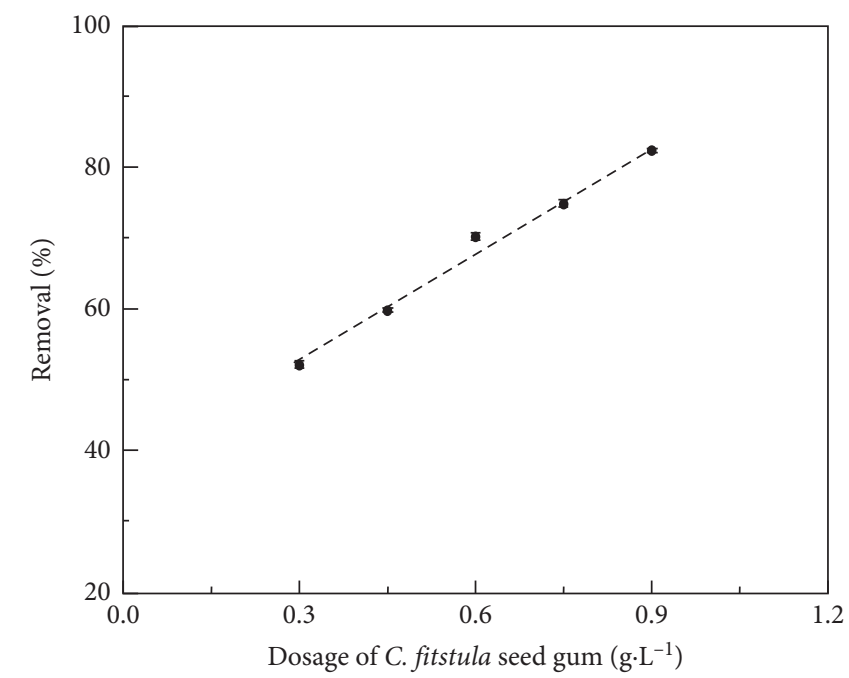

FIgURE 7: A linear plot of percentage removal versus coagulant dosage.

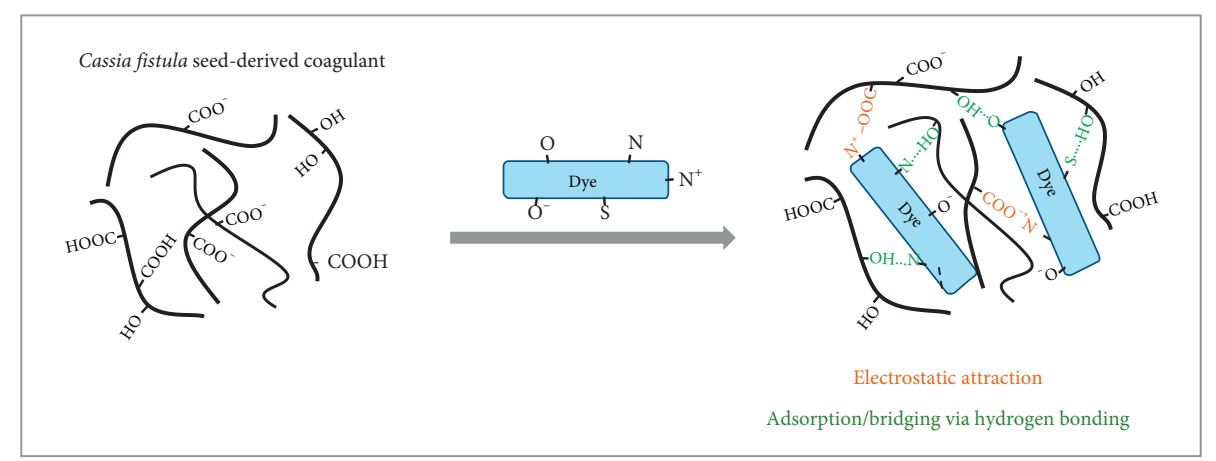

FIGURE 8: A proposed mechanism of coagulation-flocculation process.

load of pollutants, the number of secondary treatment units required, or eliminating biological process $[39,40]$. These results indicated that $C$. fistula seed gum is an effective and promising material for textile wastewater treatment using a coagulation-flocculation process.

\subsubsection{Proposed Mechanism of Coagulation-Flocculation} Process. Depending on the properties of the surface sites, charges, type of pollutant, and solution chemistry of the aqueous phase, coagulation-flocculation might involve one or more mechanisms [41]. In this study, the results obtained supported the hypothesis that adsorption/bridging and electrostatic attraction should be the predominant mechanisms for dye-based wastewater treatment. The proposed mechanisms are illustrated in Figure 8. In aqueous media, C. fistula coagulant contains long polymeric chains exposing carboxyl $\left(-\mathrm{COO}^{-} / \mathrm{COOH}\right)$ and hydroxyl $(-\mathrm{OH})$ functional groups. The negatively charged surface of the coagulant is created by the partial deprotonation of the carboxylic functional groups. These negative charges could provide the adsorption sites for the cationic dye pollutants present in real textile wastewater. On the other hand, as the C. fistula coagulant could also remove anionic RR-195 effectively at 
low $\mathrm{pH}$, the bridging mechanism through hydrogen interaction would also be involved in the coagulation-flocculation process. This interaction can be driven via hydrogen bonding between the hydroxyl groups of the coagulant and the $\mathrm{N}_{-}, \mathrm{O}_{-}$, and/or S-containing groups of the dyes.

\section{Conclusions}

The C. fistula-derived coagulant was successfully formed with rough and irregular surface. The screening experiments at bench-scale revealed that the removal efficiency was strongly dependent on coagulant dosage, initial $\mathrm{pH}$, and pollutant concentration. The pilot-scale study operated to simulate the full-scale treatment revealed that the coagulation-flocculation process using $C$. fistula seed gum was an effective primary method with the percentage removal of $93.83 \%$. The mechanism of dye-based wastewater treatment using C. fistula seed gum is mainly driven by adsorption and bridging interaction via hydrogen bonding and electrostatic attraction between opposite charges of the coagulant and dyes. This study indicates that natural coagulant derived from C. fistula seed exhibited a great potential for real domestic textile wastewater treatment. It can be developed to provide an economical, efficient, and environmentally friendly wastewater treatment.

\section{Data Availability}

The data used to support the findings of this study are included within the article.

\section{Conflicts of Interest}

The authors declare no conflicts of interest.

\section{Acknowledgments}

This research was funded by Thu Dau Mot University under grant number DT.21.1-034.

\section{References}

[1] S. Edebali, Y. Oztekin, and G. Arslan, "Metallic engineered nanomaterial for industrial use," in Handbook of Nanomaterials for Industrial Applications, Elsevier, Amsterdam, Netherland, 2018.

[2] C. Namasivayam, D. Sangeetha, and R. Gunasekaran, "Removal of anions, heavy metals, organics and dyes from water by adsorption onto a new activated carbon from jatropha husk, an agro-industrial solid waste," Process Safety and Environmental Protection, vol. 85, no. 2, pp. 181-184, 2007.

[3] M. Wołowiec, M. Komorowska-Kaufman, A. Pruss, G. Rzepa, and T. Bajda, "Removal of heavy metals and metalloids from water using drinking water treatment residuals as adsorbents: a review," Minerals, vol. 9, no. 8, pp. 487-503, 2019.

[4] H. Ali, E. Khan, and I. Ilahi, "Environmental chemistry and ecotoxicology of hazardous heavy metals: environmental persistence, toxicity, and bioaccumulation," Journal of Chemistry, vol. 2019, Article ID 6730305, 14 pages, 2019.

[5] V. K. Gupta and Suhas, "Application of low-cost adsorbents for dye removal - a review," Journal of Environmental Management, vol. 90, no. 8, pp. 2313-2342, 2009.
[6] G. Crini, "Non-conventional low-cost adsorbents for dye removal: a review," Bioresource Technology, vol. 97, no. 9, pp. 1061-1085, 2006.

[7] M. Alipour, M. Vosoughi, S. A. Mokhtari et al., "Optimising the basic violet 16 adsorption from aqueous solutions by magnetic graphene oxide using the response surface model based on the box-Behnken design," International Journal of Environmental Analytical Chemistry, vol. 101, no. 6, pp. 758-777, 2021.

[8] S. Afshin, Y. Rashtbari, M. Vosoughi et al., "Removal of basic blue-41 dye from water by stabilized magnetic iron nanoparticles on clinoptilolite zeolite," Revista de Chimie, vol. 71, no. 2, pp. 218-229, 2020.

[9] A. Hamzezadeh, Y. Rashtbari, S. Afshin, M. Morovati, and M. Vosoughi, "Application of low-cost material for adsorption of dye from aqueous solution," International Journal of Environmental Analytical Chemistry, pp. 1-16, 2020.

[10] M. T. Yagub, T. K. Sen, S. Afroze, and H. M. Ang, "Dye and its removal from aqueous solution by adsorption: a review," Advances in Colloid and Interface Science, vol. 209, pp. 172184, 2014.

[11] D. Bhatia, N. R. Sharma, J. Singh, and R. S. Kanwar, "Biological methods for textile dye removal from wastewater: a review," Critical Reviews in Environmental Science and Technology, vol. 47, no. 19, pp. 1836-1876, 2017.

[12] V. Katheresan, J. Kansedo, and S. Y. Lau, "Efficiency of various recent wastewater dye removal methods: a review," Journal of Environmental Chemical Engineering, vol. 6, no. 4, pp. 4676-4697, 2018.

[13] F. Fu and Q. Wang, "Removal of heavy metal ions from wastewaters: a review," Journal of Environmental Management, vol. 92, no. 3, pp. 407-418, 2011.

[14] S. Afshin, Y. Rashtbari, M. Shirmardi, M. Vosoughi, and A. Hamzehzadeh, "Adsorption of Basic Violet 16 dye from aqueous solution onto mucilaginous seeds of Salvia sclarea: kinetics and isotherms studies," Desalination and Water Treatment, vol. 161, pp. 365-375, 2019.

[15] G. Crini and E. Lichtfouse, "Advantages and disadvantages of techniques used for wastewater treatment," Environmental Chemistry Letters, vol. 17, no. 1, pp. 145-155, 2019.

[16] S. S. Moghaddam, M. R. Moghaddam, and M. Arami, "Coagulation/flocculation process for dye removal using sludge from water treatment plant: optimization through response surface methodology," Journal of Hazardous Materials, vol. 175, no. 1-3, pp. 651-657, 2010.

[17] H. Cui, X. Huang, Z. Yu, P. Chen, and X. Cao, “Application progress of enhanced coagulation in water treatment," $R S C$ Advances, vol. 10, no. 34, pp. 20231-20244, 2020.

[18] P. G. S. Arockiam JeyaSundar, A. Ali, d. Guo, and Z. Zhang, "Waste treatment approaches for environmental sustainability," in Microorganisms for Sustainable Environment and Health, pp. 119-135, Elsevier, Amsterdam, Netherland, 2020.

[19] S. Gautam and G. Saini, "Use of natural coagulants for industrial wastewater treatment," Global Journal of Environmental Science and Management, vol. 64, no. 4, pp. 553-578, 2020.

[20] K. P. Y. Shak and T. Y. Wu, "Optimized use of alum together with unmodified Cassia obtusifolia seed gum as a coagulant aid in treatment of palm oil mill effluent under natural $\mathrm{pH}$ of wastewater," Industrial Crops and Products, vol. 76, pp. 1169-1178, 2015.

[21] K. P. Y. Shak and T. Y. Wu, "Coagulation-flocculation treatment of high-strength agro-industrial wastewater using natural Cassia obtusifolia seed gum: treatment efficiencies and 
flocs characterization," Chemical Engineering Journal, vol. 256, pp. 293-305, 2014.

[22] H. M. Bui, Y. S. Perng, and H. G. T. Duong, "The use of artificial neural network for modelling coagulation of reactive dye wastewater using Cassia fistula Linn. gum," J Environ Sci and Manag, vol. 19, no. 1, pp. 1-8, 2016.

[23] P. Arulmathi, C. Jeyaprabha, P. Sivasankar, and V. Rajkumar, "Treatment of textile wastewater by coagulation-flocculation process using Gossypium herbaceum and polyaniline coagulants," Clean-Soil, Air, Water, vol. 47, no. 7, pp. 1-10, 2019.

[24] N. V. C. Ngan, L. T. D. Thuy, and D. M. Trung, "Apply Cassia Fistula seed gum as auxiliary bio-coagulant for fish processing wastewater treatment," International Journal of Advanced Scientific Research and Management, vol. 2, no. 8, pp. 46-51, 2017.

[25] D. M. Trung, L. H. Anh, N. T. K. Tuyen, and N. V. C. Ngan, "Effectiveness on color and COD of textile wastewater removing by biological material obtained from Cassia fistula seed," Journal of Vietnamese Environment, vol. 8, no. 2, pp. 121-128, 2016.

[26] H. A. Pawar and K. G. Lalitha, "Isolation, purification and characterization of galactomannans as an excipient from Senna tora seeds," International Journal of Biological Macromolecules, vol. 65, pp. 167-175, 2014.

[27] L. M. da Silva, L. F. S. Araújo, R. C. Alvez et al., "Promising alternative gum: extraction, characterization, and oxidation of the galactomannan of Cassia fistula," International Journal of Biological Macromolecules, vol. 165, pp. 436-444, 2020.

[28] F. J. E. T. Andrade, P. B. S. De Albuquerque, J. R. P. C. De Seixas et al., "Influence of Cassia grandis galactomannan on the properties of sponge cakes: a substitute for fat," Food \& Function, vol. 9, no. 4, pp. 2456-2468, 2018.

[29] F. Lei, Y. J. Yi, N. S. Ping, W. Y. Qun, and X. M. Yong, "Structure and conformation characterization of galactomannan from seeds of Cassia obtusifolia," Food Hydrocoll, vol. 76, pp. 67-77, 2018.

[30] W. Subramonian, T. Y. Wu, and S.-P. Chai, "A comprehensive study on coagulant performance and floc characterization of natural Cassia obtusifolia seed gum in treatment of raw pulp and paper mill effluent," Industrial Crops and Products, vol. 61, pp. 317-324, 2014.

[31] M. Anvari, M. Tabarsa, R. Cao et al., "Compositional characterization and rheological properties of an anionic gum from Alyssum homolocarpum seeds," Food Hydrocolloids, vol. 52, pp. 766-773, 2016.

[32] K. K. T. Goh, L. Matia-Merino, J. H. Chiang, R. Quek, S. J. B. Soh, and R. G. Lentle, "The physico-chemical properties of chia seed polysaccharide and its microgel dispersion rheology," Carbohydrate Polymers, vol. 149, pp. 297-307, 2016.

[33] P. Pal, "Industry-specific water treatment," in Industrial Water Treatment Process Technology, Elsevier, Amsterdam, Netherland, 2017.

[34] J. Ma, K. Fu, L. Jiang et al., "Flocculation performance of cationic polyacrylamide with high cationic degree in humic acid synthetic water treatment and effect of kaolin particles," Separation and Purification Technology, vol. 181, pp. 201-212, 2017.

[35] L. Zhou, H. Zhou, and X. Yang, "Preparation and performance of a novel starch-based inorganic/organic composite coagulant for textile wastewater treatment," Separation and Purification Technology, vol. 210, pp. 93-99, 2019.

[36] T. D. Nguyen, V. T. Bui, and N. H. Nguyen, "A study on the application of Fenton process followed by coagulation for treatment of landfill leachate," Vietnam Journal of Chemistry, vol. 58, no. 6, pp. 792-797, 2020.

[37] D. D. D. Nguyen, C. N. T. Nguyen, K. A. Huynh, and T. P. Nguyen, "Optimization of electro-Fenton process for the removal of non-biodegradable organic compounds in instant coffee production wastewater using composite $\mathrm{Fe}_{3} \mathrm{O}_{4}-\mathrm{Mn}_{3} \mathrm{O}_{4}$ nanoparticle catalyst," Research on Chemical Intermediates, vol. 45, no. 11, pp. 5341-5356, 2019.

[38] A. A. Tatsi, A. I. Zouboulis, K. A. Matis, and P. Samaras, "Coagulation-flocculation pretreatment of sanitary landfill leachates," Chemosphere, vol. 53, no. 7, pp. 737-744, 2003.

[39] I. M. Ismail, A. S. Fawzy, N. M. Abdel-Monem, M. H. Mahmoud, and M. A. El-Halwany, "Combined coagulation flocculation pre treatment unit for municipal wastewater," Journal of Advanced Research, vol. 3, no. 4, pp. 331-336, 2012.

[40] X. Xie, H. Zhou, C. Chong, and B. Holbein, "Coagulation assisted membrane filtration to treat high strength wastewater from municipal solid waste anaerobic digesters," Journal of Environmental Engineering and Science, vol. 7, no. 1, pp. 2128, 2008.

[41] S. Sonal and B. K. Mishra, "Role of coagulation/flocculation technology for the treatment of dye wastewater: trend and future aspects," Water pollution and management practices, vol. 303, 2021. 